\title{
Informing Decisions to Prevent Genocide
}

\section{Paul Slovic, Daniel Västfjäll and Robin Gregory}

This paper describes a psychological phenomenon called psychic numbing that devalues lives when many are at stake and thus enables political leaders to neglect mass suffering, in violation of our professed humanitarian values. The authors argue for the need to use tools such as decision analysis to overcome this moral insensitivity and provide a more thoughtful and consistent framework within which to assess the difficult trade-offs posed by decisions involving mass atrocities.

In an address to the nation last March, President Obama put forth his rationale for joining NATO in a military mission to protect the lives of Libyan civilians. Faced with "the prospect of violence on a horrific scale," he argued that "Some nations may be able to turn a blind eye to atrocity in other countries. The United States of America is different. And, as President, I refuse to wait for the images of slaughter and mass graves before taking action." At the same time, the president observed that we were not taking similar actions in other lands where atrocities were taking place: "America should not be expected to police the world, particularly when we have so many pressing needs here at home."

As we shall discuss later, America has all too often failed to act in the face of genocide and other mass atrocities. Perhaps the United States acted in Libya because all of the political, military, and economic factors that usually trump human rights were in sync, for once, with humanitarian objectives. One suspects, however, that when the saving of human lives comes in conflict with other strategic objectives, the latter are invariably given disproportionate weight.

Paul Slovic is President of Decision Research and Professor of Psychology at the University of Oregon. Daniel Västfjäll is a Research Scientist at Decision Research and Professor of Cognitive Psychology at Linköping University in Sweden. Robin Gregory is Associate Director of the Eco-Risk Research Unit at the University of British Columbia and Director of Value Scope Research. Support for this paper has been provided by The William and Flora Hewlett Foundation and by the U.S. National Science Foundation through Grant SES-1024808 to Decision Research. 


\section{Background and Theory: Affect and Analysis in Situations of Risk}

Risk management in the modern world relies upon two forms of thinking. ${ }^{1}$ Risk as feelings refers to our instinctive and intuitive reactions to danger. Risk as analysis brings logic, reason, quantification, and deliberation to

Compared to analysis, reliance on feelings tends to be a quicker, easier, and more efficient way to navigate in a complex, uncertain, and dangerous world. Hence, it is essential to rational behavior. Yet it sometimes misleads us. In such circumstances we need to ensure that reason and analysis also are employed.

bear on hazard management. Compared to analysis, reliance on feelings tends to be a quicker, easier, and more efficient way to navigate in a complex, uncertain, and dangerous world. Hence, it is essential to rational behavior. Yet it sometimes misleads us. In such circumstances we need to ensure that reason and analysis also are employed.

Although the visceral emotion of fear certainly plays a role in risk as feelings, we focus here on the "faint whisper of emotion" called affect and how it contributes to, or in some cases, undermines effective decision-making in the face of mass atrocities. As used here, affect refers to specific feelings of "goodness" or "badness" experienced with or without conscious awareness. Positive and negative feelings occur rapidly and automatically; note how quickly you sense the feelings associated with the word joy or the word hate. A large research literature in psychology documents the importance of affect in (1) conveying meaning upon information and (2) motivating behavior. Without affect, information lacks meaning and will not be used in judgment and decision-making.

Risk as feelings clearly employs both imagery and affect in remarkably accurate and efficient ways, but this way of responding to risk also has a darker, non-rational side. Affect may misguide us in important ways. Particularly problematic is the difficulty of comprehending the meaning of catastrophic losses of life when relying on feelings. Research reviewed below shows that disaster statistics, no matter how large the numbers, lack emotion or feeling. As a result, they fail to convey the true meaning of such calamities and they fail to motivate proper action to prevent them.

The psychological factors underlying insensitivity to large-scale loss of life apply to catastrophic harm resulting from human malevolence, natural disasters, and technological accidents. In particular, the psychological account described here can explain, in part, the failure to respond to the diffuse and seemingly distant threat posed by global warming or the presence of nuclear weaponry. Similar insensitivity may also underlie our failure to respond adequately to problems of violence, famine, poverty, and disease afflicting large numbers of people around the world. 


\section{Facing Catastrophic Loss of Life: The Darfur Genocide}

Since February 2003, hundreds of thousands of people in the Darfur region of western Sudan, Africa, have been murdered by government-supported militias, and millions have been forced to flee their burned-out villages for the dubious safety of refugee camps. This has been well-documented, yet the world looks away. The events in Darfur are the latest in a long list of mass murders since World War II to which powerful nations and their citizens have responded with indifference. In her Pulitzer Prize-winning book $A$ Problem from Hell: America and the Age of Genocide, Samantha Power documents in meticulous detail many of the numerous genocides that occurred during the past century. In every instance, American response was inadequate. She concludes: "No U.S. president has ever made genocide prevention a priority, and no U.S. president has ever suffered politically for his indifference to its occurrence. It is thus no coincidence that genocide rages on."

The United Nations General Assembly adopted the Convention on the Prevention and Punishment of the Crime of Genocide in 1948 in the hope that "never again" would there be such odious crimes against humanity as occurred during the Holocaust of World War II. Eventually some 140 states would ratify the Genocide Convention, yet it has never been invoked to prevent a potential attack or halt an ongoing massacre. Darfur stands out as a particularly harsh example of the failures to intervene in genocide. As Richard Just ${ }^{3}$ has observed, "we are awash in information about Darfur. . . $[\mathrm{N}]$ o genocide has ever been so thoroughly documented while it was taking place ... but the genocide continues. We document what we do not stop. The truth does not set anybody free. ${ }^{4}$... [H] ow could we have known so much and done so little?"5

\section{Affect and the Value of Human Lives}

This brings us to a crucial question: How should we value the saving of human lives? An analytic answer would look to basic principles or fundamental values for guidance. For example, Article 1 of the U.N. Universal Declaration of Human Rights asserts that "[a]ll human beings are born free and equal in dignity and rights." 6 We might infer from this the conclusion that every human life is of equal value. If so, then-applying a rational calculation-the value of saving $N$ lives is $N$ times the value of saving one life, as represented by the linear function in Figure 1.

An argument can also be made for judging large losses of life to be disproportionately more serious because they threaten the social fabric and viability of a group or community (see Figure 2). Debate can be had at the margins over whether one should assign greater value to younger people versus the elderly, or whether governments have a duty to give more weight to the lives of their own people, and so on, but a perspective approximating the equality of human lives is rather uncontroversial.

How do we actually value human lives? Research provides evidence in support of two descriptive models linked to affect and intuitive thinking that reflect values for lifesaving profoundly different from those depicted 


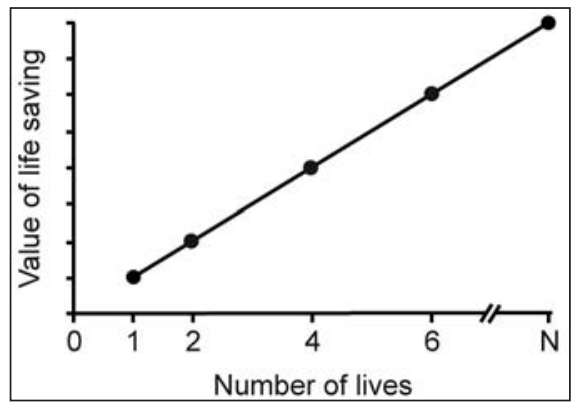

Figure 1.

A normative model for valuing the saving of human lives. Every human life is of equal value.?

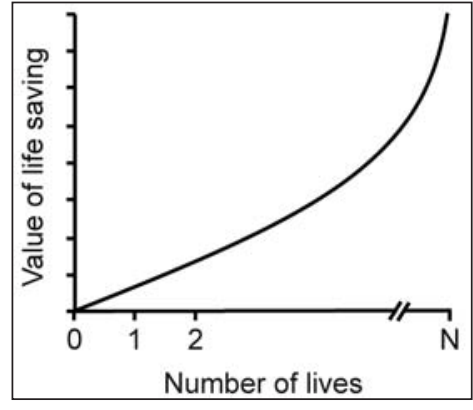

Figure 2.

Another normative model: Large losses threaten the viability of the group or society.

in the normative (rational) models shown in Figures 1 and 2. Both of these descriptive models demonstrate responses that are insensitive to large losses of human life, consistent with apathy toward genocide.

\section{Model 1: Psychophysical Numbing}

There is considerable evidence that our affective responses and the resulting value we place on saving human lives follow the same sort of "psychophysical function" that characterizes our diminished sensitivity to changes in a wide range of perceptual and cognitive entities-brightness, loudness, heaviness, and wealth-as their underlying magnitudes increase.

As psychophysical research indicates, constant increases in the magnitude of a stimulus typically evoke smaller and smaller changes in response. Applying this principle to the valuing of human life suggests that a form of psychophysical numbing may result from our inability to appreciate losses of life as they become incrementally larger. The function in Figure 3 represents a value structure in which the importance of saving one life is great when it is the first, or only, life saved but diminishes as the total number of lives at risk increases. Thus, psychologically, the importance of saving one life pales against the background of a larger threat: We may not "feel" much difference, nor value the difference, between saving 87 lives or saving 88 .

Fetherstonhaugh, Slovic, Johnson, and Friedrich ${ }^{8}$ demonstrated this potential for psychophysical numbing in the context of evaluating people's willingness to fund various lifesaving interventions. In a study involving a hypothetical grant funding agency, respondents were asked to indicate the number of lives a medical research institute would have to save to merit receipt of a $\$ 10$ million grant. Nearly two-thirds of the respondents raised 


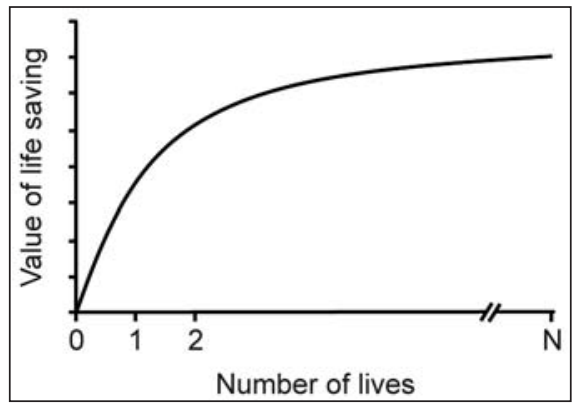

Figure 3.

A psychophysical model describing how the saving of human lives may actually be valued.

their minimum benefit requirements to warrant funding when there was a larger at-risk population, with a median value of 9,000 lives needing to be saved when 15,000 were at risk (implicitly valuing each life saved at \$1,111), compared to a median of 100,000 lives needing to be saved out of 290,000 at risk (implicitly valuing each life saved at \$100). Thus respondents saw saving 9,000 lives in the smaller population as more valuable than saving more than ten times as many lives in the larger population. The same study also found that people were less willing to send aid that would save 4,500 lives in Rwandan refugee camps as the size of the camps' at-risk population increased.

In recent years, vivid images of natural disasters in South Asia and the American Gulf Coast, and stories of individual victims there, brought to us through relentless, courageous, and intimate news coverage, unleashed an outpouring of compassion and humanitarian aid from all over the world. Perhaps there is hope here that vivid, personalized media coverage featuring victims could also motivate intervention to halt the killing.

Perhaps. Research demonstrates that people are much more willing to aid identified individuals than unidentified or statistical victims. A cautionary note comes from a study in which Small, Loewenstein, and Slovic ${ }^{9}$ gave people who had just participated in a paid psychological experiment the opportunity to contribute up to $\$ 5$ of their earnings to the charity Save the Children. In one condition, respondents were asked to donate money to feed an identified victim, a seven-year-old African girl named Rokia, of whom they were shown a picture. They contributed more than twice the amount given by a second group who were asked to donate to the same organization working to save millions of Africans (statistical lives) from hunger. Respondents in a third group were asked to donate to Rokia, but were also shown the larger statistical problem (millions in need) shown to the second group. Unfortunately, coupling the large-scale statistical realities with Rokia's story significantly reduced contributions to Rokia (see Figure 4).

Why did this occur? Perhaps the presence of statistics reduced the attention to Rokia essential for establishing the emotional connection necessary to motivate donations. Alternatively, recognition of the millions who would not be helped by one's small donation may have produced negative feelings that inhibited donations. Note the similarity here at the individual level to the failure to help 4,500 people in the larger refugee camp. The rationality of these responses can be questioned. Why be deterred from 


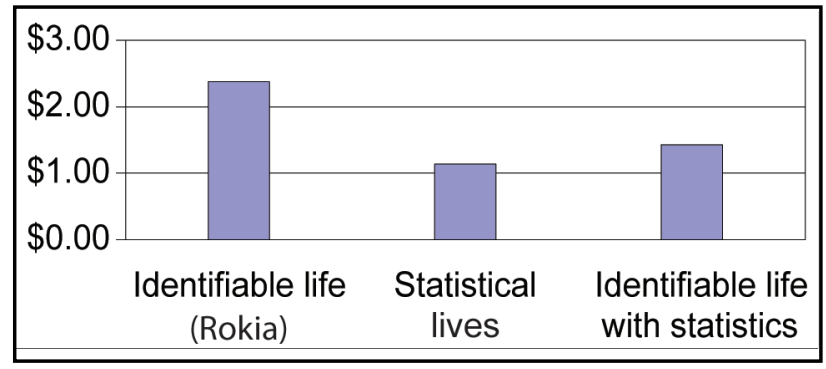

Figure 4.

Mean donations. ${ }^{10}$

helping 1 person or 4,500 people just because there are many others who cannot be saved?

In sum, research on psychophysical numbing is important because it demonstrates that feelings necessary for motivating lifesaving actions are not congruent with the normative and rational models in Figures 1 and 2 . The nonlinearity displayed in Figure 3 is consistent with the devaluing of incremental increases in loss of life in the context of large-scale tragedy. It thus explains why we do not feel any different upon learning that the death toll in Darfur is closer to 400,000 than to 200,000 . What it does not fully explain, however, is apathy toward genocide, inasmuch as it implies that the response to initial loss of life will be strong and maintained, albeit with diminished sensitivity, as the losses increase. Evidence for a second descriptive model, better suited to explain apathy toward large losses of lives, follows.

\section{Model 2: The Collapse of Compassion}

The American writer Annie Dillard ${ }^{11}$ reads in her newspaper the headline "Head Spinning Numbers Cause Mind to Go Slack." She writes of "compassion fatigue" and asks, "At what number do other individuals blur for me?"12

An answer to Dillard's question is beginning to emerge from behavioral research. Studies by social psychologists find that a single individual, unlike a group, is viewed as a psychologically coherent unit. This leads

Studies by social psychologists find that a single individual, unlike a group, is viewed as a psychologically coherent unit. This leads to more extensive processing of information and stronger impressions about individuals than about groups. to more extensive processing of information and stronger impressions about individuals than about groups. Consistent with this, a study in Israel found that people tend to feel more distress and compassion and to provide more aid when considering a single victim than when considering a group of eight victims. ${ }^{13} \mathrm{~A}$ follow-up study in Sweden found that people felt less compassion and donated less aid toward a pair of victims than to either individual alone. ${ }^{14}$ Perhaps the blurring that Annie Dillard asked about begins for groups as small as two people. 
The insensitivity to lifesaving portrayed by the psychophysical-numbing model is unsettling. But the studies just described suggest an even more disturbing psychological tendency. Our capacity to feel is limited. To the extent that valuation of lifesaving depends on feelings driven by attention or imagery, it might follow the function shown in Figure 5, where the emotion or affective feeling is greatest at $N=1$ but begins to decline at $N=2$ and collapses at some higher value of $N$ that becomes simply "a statistic." Whereas Robert J. Lifton coined the term psychic numbing to describe the "turning off" of feeling that enabled rescue workers to function during the horrific aftermath of the Hiroshima bombing, ${ }^{15}$ Figure 5 depicts a form of psychic numbing that is not beneficial. Rather, it leads to apathy and inaction, consistent with what is seen repeatedly in response to mass murder and genocide.

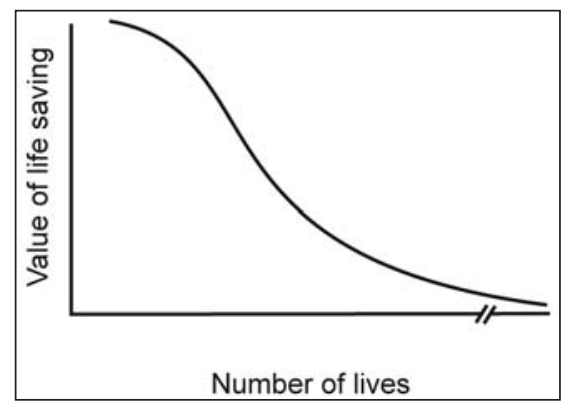

Figure 5.

A model depicting psychic numbing-the collapse of compassion-when valuing the saving of lives.

\section{Intuition, Analysis, and the Value of Human Lives}

Consider how we typically deal with risk. Long before probability theory, risk assessment, and other methods of analysis had been invented, there were such faculties as intuition, instinct, and gut feeling, which, honed by experience, told us whether an animal was safe to approach or water safe to drink. As life became more complex and humans gained more control over their environment, analytic ways of thinking evolved to boost the rationality of our experiential reactions. Beyond the question of how water looks and tastes, we now can look to toxicology and analytic chemistry to tell us whether it is safe to drink. We can still use our feelings, but in addition, we have results from analyses to guide our choices. ${ }^{16}$

As with risk, the natural and easy way to deal with moral issues is to rely on our intuitions: "How bad is it?" Well, how bad does it feel? Here again we can apply reason and logical analysis to help distinguish right from wrong, as our legal system attempts to do. Nevertheless, as the psychologist Jonathan Haidt has demonstrated, moral intuition comes first and usually dominates moral judgment unless we make an effort to critique, and if necessary, override our intuitive feelings. ${ }^{17}$ 
One response to the insensitivity and psychological numbing accompanying moral intuition is to apply moral judgment to incorporate into decision processes the use of an analytical structure that articulates the range of costs and benefits associated with decisions about genocide, and most importantly, to clarify and structure the attendant trade-offs. This organizational function of analytic processes may not be needed when the problem facing a decision maker is simple or when solutions easily align with prior experience. However, neither of these descriptors fit the usual choices for intervention possibilities in the face of potential mass atrocities: Such decisions are typically complex in that they involve a diverse mix of moral, economic, safety, and political considerations. They also typically involve a context that in some ways is considered to be unusual or even unique.

One of the important reasons to consider the use of analytical methods is that, left to its own devices, moral intuition will likely favor individual victims and sen-

Rather than solely focusing on obligations to act, international and domestic law could also require policy makers and governmental actors to reason about actions to take in order to overcome psychic numbing and to encourage a response to genocide that reflects both analytical and intuitive modes of thinking. sational stories that are close to home and easy to imagine. Our sizable capacity to care for others may be demotivated by negative feelings resulting from thinking about those we cannot help. Or it may be overridden by economic and political interests brought into play when mass atrocities occur in distant lands. Compassion for others has been characterized by social psychologist Daniel Batson as "a fragile flower, easily crushed by self-concern." 18 Faced with genocide and other mass tragedies, we cannot rely on our intuitions alone to guide us to act properly.

\section{Implications for Policy and Deliberation}

Even though emotion and affect may let us down, we still can be spurred into action if we can employ a decision-making process capable of weighing the costs and benefits of possible intervention options in the face of mass human rights violations. Rather than solely focusing on obligations to act, international and domestic law could also require policy makers and governmental actors to reason about actions to take in order to overcome psychic numbing and to encourage a response to genocide that reflects both analytical and intuitive modes of thinking. 


\section{A Decision Analytic Perspective}

An approach commonly known as decision analysis ${ }^{19}$ has been used widely to address a variety of other public policy choices characterized by the same type of emotional, health-based and ethics-based trade-offs that can lead feelings to override more thoughtful analysis. Decision-analytic methods seek first to identify a small set of key concerns and then generate and evaluate policy alternatives in terms of how their consequences are likely to affect these key objectives. ${ }^{20}$ A primary contribution is simply to structure difficult choices and options that involve multiple dimensions of value carefully; often the various possible actions are subject to controversy or disagreement among participating stakeholders and, in many cases, the outcomes of these actions are also subject to substantial uncertainty. ${ }^{21}$

At first glance, decision analysis and human rights may appear to stand in opposition, with the human suffering involved in genocide or mass starvation seemingly at odds with a more dispassionate, quantitative approach to problem solving. Yet any dialogue among government leaders concerning the choice to intervene or stand by in the face of reports concerning human rights violations necessarily involves dimensions other than those directly concerned with the victims' suffering: the costs of providing assistance, the potential risks to those providing military or humanitarian aid, the domestic and international implications of action or inaction, and so forth. Decision makers who face tough trade-offs across this array of impacts can easily feel overwhelmed, and as a result, decision quality suffers. For example, research has shown that when faced with multi-dimensional choices that include disparate values (e.g., health vs. cost) and ethical principles, people often resort to lexicographic choice patterns in which they focus only on a single dimension of value, to the neglect of other important considerations. ${ }^{22}$

A critical element of this decision-aiding process is coming up with good measures to track the performance of different policies. Experience shows that it's relatively easy to identify broad terms that might help to evaluate contemplated actions-intended to enhance democratic institutions, reduce famine, or assist coordination-but, so long as these concerns remain abstractions, different people may disagree about the extent to which a specific policy alternative addresses them. As a result, decision analytic methods highlight the role of performance measures (or attributes) that seek to operationalize key considerations and develop concise, agreed-upon measures that define these concepts. ${ }^{23}$ Some concerns, such as costs, have natural indicators and are easily understood (e.g., dollars or euros). Other concerns, such as hunger, are more difficult to define or quantify but have readily understood, albeit imperfect, proxies; the daily caloric intake of an average individual, for example, is one possible measure. In other cases, it may be necessary to construct special scales for the specific case under consideration. Achievement of concerns such as gaining local public support, for example, may be tracked using a 1-5 scale whereby a rating of 1 denotes very low levels of support, a 3 moderate support, and a 5 very high support. Such measures are only approximations, of course, but they provide a means by which the full range of possible impacts accompanying an action can be 
placed on the table and considered by decision makers. Further, different levels of detail are possible: for example, indices of this type can be accompanied by careful explanatory narratives or multiple measures can be used to depict more nuanced or complex issues.

\section{The Role of Group Deliberation}

Often decisions involving actions to prevent large-scale losses of human lives are made by groups rather than by individuals; for example, a cabinet of ministers or key advisors may be asked to contribute their opinions about the pros and cons of possible intervention strategies to a national president or prime minister. Recognition of this group-based deliberative environment suggests the importance of constructing a policy response that facilitates effective deliberation. Experience from other decision contexts that require policy makers to balance a range of costs and benefits ${ }^{24}$ indicates that this simple act of engaging in structured dialogue may help overcome both affective and cognitive obstacles to intervention and, in many cases, could help to generate new actions that might not otherwise be considered.

What might effective group deliberation require? At a minimum, group members faced with the difficult task of developing a defensible policy should make use of a common structure and language for expressing and communicating their feelings and thoughts. The same deliberative structure should serve as a guide to national or to international discussions and should provide a detailed rationale in the case of omissions (e.g., the failure to respond meaningfully to a genocide) as well as actions. Decision analysis approaches again provide a useful model, in that they have been widely used to help structure objectives, facilitate the creation of responsive options, and assist shared decision making among members of groups for a variety of complex public-policy problems. ${ }^{25}$ Importantly, the discipline and interactive structure of decision analysis, informed by behavioral decision research, offers explicit procedures and standards for what should be included as part of a responsible group deliberative process-one that addresses both the cognitive and the emotional demands that typically arise as part of generating, understanding, and evaluating complex policy options. ${ }^{26}$

\section{Change the Basis for Human Rights Deliberations}

As noted at the outset, one of the difficulties in addressing human rights decisions is that this typically involves a range of seemingly incommensurable value dimensions. Choices of this type are often made on the basis of intuition or "gut feeling" in the absence of a defensible framework or guidelines. One result is that decision makers are likely to evaluate the pros and cons of actions in each new situation or crisis on an ad hoc and inconsistent basis, without sufficient deliberation or peer review. Another result is that at least some key considerations are likely to remain poorly defined or, perhaps, entirely omitted from deliberations at the same time that other concerns are given undue weight and influence. A third common result is that the development of standards that might encourage learning about genocide-prevention decisions and make it easier over time for lessons 
gained from one experience to inform later evaluations is less likely to take place. Instead, each decision may be viewed as a one-off dilemma. Hillary Clinton expressed this difficulty well in a March 2011 interview with Ryan Lizza in Tunis:

I get up every morning and I look around the world. People are being killed in Cote d'Ivoire, they're being killed in the Eastern Congo, they're being oppressed and abused all over the world by dictators and really unsavory characters. So we could be intervening all over the place. But this is not a-what is the standard? Is the standard, you know, a leader who won't leave office in Ivory Coast and is killing his own people? Gee, that sounds familiar. So part of it is having to make tough choices and wanting to help the international community accept responsibility. ${ }^{27}$

The lack of a clear analytic framework is a serious shortcoming, particularly when the decision contexts are as significant as those brought to mind by modern examples of genocide. Fortunately, there exist a variety of practical tools drawn from the insights and practices of psychologists and decision analysts that can help to inform deliberations about the development of a defensible decision-making framework concerning decisions to prevent mass atrocities. Over time, these methods could assist U.S. policymakers to adopt a more responsible approach to dealing with the tough issues and trade-offs raised by emerging problems of genocide quickly and effectively.

Figure 6 illustrates a simple approach that has been widely used to help decision makers organize their thinking and deliberate more effectively about complex, multi-issue, and multi-stakeholder problems. This deceptively visual tool is called a "consequence matrix" 28 or, in some circles, a "facts box." The rows report a set of critical concerns defined in terms of specified performance measures with a preferred direction (either more or less is better). The columns to the right represent alternative policies or actions scored or rated by filling in each of the cells of the matrix in terms of how well the various consequences of the alternative are expected to achieve progress on each of the specified objectives. In a typical case there is considerable variation: one action or intervention policy might be best in terms of anticipated domestic support but rate poorly in terms of financial costs, whereas a second alternative might maximize the expected effectiveness of the intervention but run the risk of causing high numbers of military casualties. Similarly, an approach that satisfies domestic objectives might run into opposition from international partners (e.g., it may involve transiting a national border illegally or without U. N. authorization). In a typical situation the objectives can be used to define an initial set of alternatives that perform well on each of the single objectives; these initial actions can then be mixed and modified to generate novel alternatives (Alternatives 4, 5 , etc.) that seek higher levels of achievement across a number of different objectives.

This same way of thinking can be expressed more formally through development of a value model that first specifies and measures the key concerns and then weights each objective (by developing a utility function 


\begin{tabular}{|c|c|c|c|c|c|}
\hline Objectives & $\begin{array}{l}\text { Performance } \\
\text { measures }\end{array}$ & $\begin{array}{l}\text { Desired } \\
\text { direction }\end{array}$ & $\begin{array}{c}\text { Alt } \\
1\end{array}$ & $\begin{array}{c}\text { Alt } \\
2\end{array}$ & $\begin{array}{c}\text { Alt } \\
3\end{array}$ \\
\hline maximize intervention effectiveness & $\begin{array}{l}\text { Constructed scale } \\
\qquad(1-5)\end{array}$ & more & & & \\
\hline maximize domestic support & $\begin{array}{l}\text { Constructed scale } \\
\qquad(1-5)\end{array}$ & more & & & \\
\hline maximize international support & $\begin{array}{l}\text { Constructed scale } \\
\qquad(1-5)\end{array}$ & more & & & \\
\hline minimize intervention costs & Dollars (millions) & less & & & \\
\hline minimize fatalities among military & Number & less & & & \\
\hline minimize fatalities in country & Number & less & & & \\
\hline $\begin{array}{l}\text { advance post-intervention economic } \\
\text { opportunities }\end{array}$ & Dollars (millions) & more & & & \\
\hline promote reform & $\begin{array}{l}\text { Constructed scale } \\
\qquad(1-5)\end{array}$ & more & & & \\
\hline
\end{tabular}

Figure 6.

Consequence matrix for clarifying intervention trade-offs.

across the identified objectives) in terms of its contribution to this specific decision context in order to more clearly identify and address the key value trade-offs. ${ }^{29}$ This weighting capability allows for a general consistency in the choice of objectives across different intervention contexts but simultaneously formally acknowledges differences across these contexts so that country-by-country strategies can be developed to meet specified needs.

\section{Encourage Deliberation-Forcing Approaches}

Pursuing a deliberative approach based on giving explicit attention to the multiple dimensions of anti-genocide efforts would not be unprecedented as a tool designed to overcome the many associated cognitive and emotional obstacles. Moreover, because it requires "only" deliberation, states may be more willing to entertain the use of decision-aiding approaches. At the international level, an additional protocol to the genocide convention could compel states to respond to the possible occurrence of genocide by producing a detailed action plan, factoring in the likely costs and benefits of different types of intervention and demonstrating the pros and cons of the different alternatives that were considered. At regular intervals, states could be required to justify failure to act based on an updated assessment of costs and benefits. And the treaty could require high-visibility public presentation of these findings before both international and domestic audiences. The reporting requirements could also specify levels of engagement at both the elite decision-making level (such as requiring the participation of the security establishment) and involvement at the popular level (such as requiring dissemination of information and hearings designed to reach the public). In addition, the U.N. Security Council could create a "Genocide 
Committee" to monitor and receive state reports and to ensure that state reports are timely and do not constitute foot-dragging. Such a committee would be analogous to the " 1540 Committee" established to monitor and coordinate national nonproliferation efforts. Finally, at the national level, legislatures and executives can require hearings and reports evaluating the various costs, risks, and benefits of intervention and nonintervention.

\section{Conclusion}

America's record on addressing genocide is a source of neither national pride nor personal comfort. In a variety of situations around the world over the past seventy-five years, U.S. decision makers have been informed in advance of pending or ongoing mass murders or genocides but have chosen to not take effective actions. As Samantha Power sadly notes, ${ }^{30}$ America's record is one of strong abstract support for principles and ideals opposed to genocide but of little or no action when a real-world situation arises that calls for immediate and effective intervention in order to prevent or halt a possible genocide.

There are many possible reasons for this consistent record of neglect. In this paper we focus on two possible explanations. First, we emphasize the role of psychology and, in particular, affective responses in shaping our reactions to

America's record is one of strong abstract support for principles and ideals opposed to genocide but of little or no action when a real-world situation arises that calls for immediate and effective intervention in order to prevent or halt a possible genocide. mass atrocities. Drawing upon behavioral research and common observation, we argue here that we cannot depend only upon our moral intuitions to motivate us to take proper action against genocide and mass abuse of human rights. This places the burden of response squarely upon moral argument and international law. Second, we emphasize the need for an explicit decision framework that can incorporate the multiple dimensions of value that influence choices about genocide and can provide insights about the pros and cons of alternative responses.

It is time to reexamine America's failure to act in the face of mass atrocities with an acknowledgment of the psychological deficiencies described in this paper and recognition of the possibilities held by decisionanalytic methods to encourage thoughtful deliberation. This is a remedy that is quite modest in that it requires only the acknowledgement of the potential to allow structured deliberations to help bridge strong emotions with the discipline of a reasoned approach. With this new model as a guide, it should be possible to design legal and institutional mechanisms that will compel us to respond to genocide and other mass harms with a degree of intensity that is commensurate with the high value we place on individual human lives. 


\section{Notes}

${ }^{1}$ Kahneman, D. (2011) Thinking, Fast and Slow (New York: Farrar, Straus and Giroux).

${ }^{2}$ Power, S. (2003) A Problem from Hell: America and the Age of Genocide (New York: Harper Perennial): xxi.

${ }^{3}$ Just, R. (2008) 'The truth will not set you free: Everything we know about Darfur and everything we're not doing about it', The New Republic, August: 36-47.

${ }^{4}$ Ibid: 36.

${ }^{5}$ Ibid: 38 .

${ }^{6}$ Full text available at: http://www.un.org/en/documents/udhr/

${ }^{7}$ The source for Figures 1-3 and 5 is Slovic, P. (2007) "If I look at the mass I will never act": Psychic numbing and genocide', Judgment and Decision Making, 2, 79-95.

${ }^{8}$ Fetherstonhaugh, D., Slovic, P., Johnson, S. M. and Friedrich, J. (1997) 'Insensitivity to the value of human life: A study of psychophysical numbing', Journal of Risk and Uncertainty, 14: 283-300.

${ }^{9}$ Small, D. A., Loewenstein, G. and Slovic, P. (2007) 'Sympathy and callousness: The impact of deliberative thought on donations to identifiable and statistical victims', Organizational Behavior and Human Decision Processes, 102: 143-53.

${ }^{10}$ Source: Small et al.

${ }^{11}$ Dillard, A. (1999) For the time being (New York: Alfred A. Knopf), 130-1.

${ }^{12}$ She struggled to think straight about the great losses that the world ignores: "More than two million children die a year from diarrhea and eight hundred thousand from measles. Do we blink? Stalin starved seven million Ukrainians in one year, Pol Pot killed two million Cambodians...." (Ibid: 130-131).

${ }^{13}$ Kogut, T. and Ritov, I. (2005) 'The “identified victim” effect: An identified group, or just a single individual?', Journal of Behavioral Decision Making, 18: 157-67.

${ }^{14}$ Slovic, op. cit.

${ }^{15}$ Lifton, R. J. (1967) Death in Life: Survivors of Hiroshima (New York: Random House).

${ }^{16}$ Arvai, J. L. and Post, K. (2011) 'Risk management in a developing country context: Improving decisions about point-of-use water treatment among the rural poor in Africa', Risk Analysis, advance online publication.

${ }^{17}$ Haidt, J. (2001) 'The emotional dog and its rational tail: A social intuitionist approach to moral judgment', Psychological Review, 108: 814-34.

${ }^{18}$ Batson, C. D., O'Quin, K., Fultz, J., Vanderplas, M. and Isen, A. (1983) 'Self-reported distress and empathy and egoistic versus altruistic motivation for helping', Journal of Personality and Social Psychology, 45: 718.

${ }^{19}$ Keeney, R. (1982) 'Decision analysis: An overview', Operations Research 30: 803-38.

${ }^{20}$ Keeney, R. and Raiffa, H. (1993) Decisions With Multiple Objectives: Preferences and Value Tradeoffs (UK: Cambridge University Press).

${ }^{21}$ Gregory, R., et al. (2012) Structured Decision Making: A Practical Guide to Environmental Management Choices (Chichester, West Sussex, UK: Wiley-Blackwell).

${ }^{22}$ Lichtenstein, S., Gregory, R., and Irwin, J. (2007), 'What's bad is easy: Taboo values, affect, and cognition', Judgment and Decision Making, 2, 169-88.

${ }^{23}$ Keeney, R. L. and Gregory, R. (2005), 'Selecting attributes to measure the achievement of objectives', Operations Research, 53, 1-11.

${ }^{24}$ Gregory R. and Keeney, R. L. (1994), 'Creating policy alternatives using stakeholder values', Management Science, 40, 1035-48.

${ }^{25}$ Edwards, W. and von Winterfeldt, D. (1987), 'Public values in risk debates', Risk Analysis, 7, 141-58; Keeney, R. L. (1988), 'Structuring objectives for problems of public interest', Operations Research, 36, 396-405.

${ }^{26}$ Gregory, R., Fischhoff, B., and McDaniels, T. (2005), 'Acceptable input: Using decision analysis to guide public decisions', Decision Analysis, 2, 4-16.

${ }^{27}$ Lizza, R.. (2011)'The Consequentialist.' The New Yorker, May 2. 
${ }^{28}$ Keeney, R. L. (1992) Value-Focused Thinking: A Path to Creative Decisionmaking (Cambridge, MA: Harvard University).

${ }^{29}$ Keeney, R. L. and von Winterfeldt, D. (2011) 'A value model for evaluating Homeland Security decisions', Risk Analysis, 31, 1470-87.

${ }^{30}$ Power, op. cit. 